\title{
Management of Cardiac Implantable Electronic Device Follow-Up in COVID-19 Pandemic: Lessons Learnt During Italian Lockdown
}

\author{
Agostino Piro ${ }^{1}$, Michele Magnocavallo ${ }^{1}$, Domenico Della Rocca ${ }^{2}$, Giovanna Manzi ${ }^{1}$, Matteo \\ Neccia $^{1}$, Alessia Bernardini ${ }^{1}$, Marco Valerio Mariani ${ }^{1}$, Martina Straito ${ }^{1}$, Paolo Severino ${ }^{1}$, \\ Giuseppe Giunta ${ }^{1}$, Gino Iannucci ${ }^{1}$, Cristina Chimenti ${ }^{1}$, Andrea Natale ${ }^{3}$, Francesco Fedele ${ }^{1}$, \\ and Carlo Lavalle ${ }^{1}$ \\ ${ }^{1}$ Sapienza University of Rome \\ ${ }^{2}$ Texas Cardiac Arrhythmia Institute \\ ${ }^{3}$ St. David's Medical Center
}

June 23, 2020

\begin{abstract}
Introduction: Remote monitoring (RM) has profoundly transformed the standard of care for patients with cardiac electronic implantable devices. It provides easy access to valuable information about arrhythmic events, acute decompensation manifestations and device-related issues without the need of continuous in-person visits. Methods: Starting March 1 st, 332 patients were introduced to a RM program during the Italian lockdown in order to limit the risk of in-hospital exposure to Severe Acute Respiratory Syndrome Coronavirus-2. Patients were categorized in two groups based on the modality of RM delivery [home $(n=229)$ vs office $(n=103)$ delivered]. The study aimed at assessing the efficacy of the new follow-up protocol, reported as the mean RM Activation Time (AT) and the need for technical support for its activation. Patients' acceptance and anxiety status was also quantified by means of the Home Monitoring Acceptance and Satisfaction Questionnaire and the Generalized Anxiety Disorder 7 -item scale. Results: AT time was $<48$ hours in $93 \%$ of patients and $7 \%$ of them required further technical support. Despite a higher number of trans-telephonic technical support in home-delivered RM group, AT was comparable between groups ( $1.33 \pm 0.83$ days in home-delivered vs $1.28 \pm 0.81$ days in office-delivered patients; $\mathrm{p}=0.60)$. Twenty-eight $(2.5 \%)$ urgent/emergent in-person examinations were planned. High degree of patient's satisfaction was reached in both groups while anxiety status was higher in office-delivered group. Conclusions: RM was effective, safe and well tolerated by patients during the Italian lockdown. Our findings confirm the efficacy of this approach to reduce in-hospital visits, guaranteeing patients' safety and quality of care.
\end{abstract}

Management of Cardiac Implantable Electronic Device Follow-Up in COVID-19 Pandemic: Lessons Learnt During Italian Lockdown

\section{Short title: A Novel CIED Workflow During COVID-19 Pandemic}

Authors. Agostino Piro, $\mathrm{MD}^{*}$; Michele Magnocavallo, $\mathrm{MD}^{*}$; Domenico Giovanni Della Rocca, $\mathrm{MD}^{+}$; Matteo Neccia, MD*; Giovanna Manzi, MD*; Marco Valerio Mariani, MD*; Martina Straito, MD*; Alessia Bernardini, MD*; Paolo Severino, $\mathrm{MD}^{*}$; Gino Iannucci $\mathrm{MD}^{++}$; Giuseppe Giunta, MD* ; Cristina Chimenti, MD*; Andrea Natale, $\mathrm{MD}^{\S}$; Francesco Fedele, $\mathrm{MD}^{*}$; Carlo Lavalle, $\mathrm{MD}^{*}$

\section{Affiliations.}

* Department of Cardiovascular, Respiratory, Nephrology, Anaesthesiology and Geriatric Sciences, "Sapienza" University of Rome, Italy. 
+ Texas Cardiac Arrhythmia Institute, St. David's Medical Center, Austin, Texas.

++ Department of Translational and Precision Medicine, Sapienza University of Rome, Italy.

SS Texas Cardiac Arrhythmia Institute, St. David's Medical Center, Austin, Texas; Interventional Electrophysiology, Scripps Clinic, La Jolla, California; Department of Cardiology, MetroHealth Medical Center, Case Western Reserve University School of Medicine, Cleveland, Ohio; Division of Cardiology, Stanford University, Stanford, California; Dell Medical School, University of Texas, Austin, Texas.

Disclosures: Dr. Natale has received speaker honoraria from Boston Scientfic, Biosense Webster, St. Jude Medical, Biotronik, and Medtronic; and is a consultant for Biosense Webster, St. Jude Medical, and Janssen. All other authors have reported that they have no relationships relevant to the contents of this paper to disclose.

Address for Correspondence: Carlo Lavalle, MD. Department of Clinical, Internal, Anesthesiology and Cardiovascular Sciences, Sapienza University of Rome, Viale del Policlinico, 155-00161 Rome, Italy. Tel: +39335376901. E-mail address: carlo.lavalle@uniroma1.it

Funding: This research did not receive any specific grant from funding agencies in the public, commercial, or not-for-profit sectors.

Introduction: Remote monitoring (RM) has profoundly transformed the standard of care for patients with cardiac electronic implantable devices. It provides easy access to valuable information about arrhythmic events, acute decompensation manifestations and device-related issues without the need of continuous inperson visits.

Methods: Starting March 1st, 332 patients were introduced to a RM program during the Italian lockdown in order to limit the risk of in-hospital exposure to Severe Acute Respiratory Syndrome Coronavirus-2. Patients were categorized in two groups based on the modality of RM delivery [home $(n=229)$ vs office $(n=103)$ delivered]. The study aimed at assessing the efficacy of the new follow-up protocol, reported as the mean RM Activation Time (AT) and the need for technical support for its activation. Patients' acceptance and anxiety status was also quantified by means of the Home Monitoring Acceptance and Satisfaction Questionnaire and the Generalized Anxiety Disorder 7-item scale.

Results: AT time was $<48$ hours in $93 \%$ of patients and $7 \%$ of them required further technical support. Despite a higher number of trans-telephonic technical support in home-delivered RM group, AT was comparable between groups (1.33+-0.83 days in home-delivered vs $1.28+-0.81$ days in office-delivered patients; $\mathrm{p}=0.60)$. Twenty-eight $(2.5 \%)$ urgent/emergent in-person examinations were planned. High degree of patient's satisfaction was reached in both groups while anxiety status was higher in office-delivered group.

Conclusions: RM was effective, safe and well tolerated by patients during the Italian lockdown. Our findings confirm the efficacy of this approach to reduce in-hospital visits, guaranteeing patients' safety and quality of care.

Key Words: COVID-19, Cardiac Implantable Electronic Device, Remote Monitoring, CIED, GAD-7.

\section{Abbreviations:}

AF: Atrial Fibrillation

CESC: Cardiac Electrophysiology and Stimulation Center

CIED: Cardiac Implantable Electronic Device

COVID-19: COronaVIrus Disease-2019

CRT: Cardiac Resynchronization Therapy

GAD-7: Generalized Anxiety Disorder 7-item 
HF: Heart Failure

HoMASQ: Home Monitoring Acceptance and Satisfaction Questionary

ICD: Implantable Cardioverter Defibrillator

ILR: Implantable Loop Recorder

IPE: In Personal Evaluation

PMK: Pacemaker

RM: Remote Monitoring

SARS-CoV2: Severe Acute Respiratory Syndrome - Coronavirus - 2

SVT: Supraventricular Tachycardia

VT: Ventricular Tachycardia

INTRODUCTION

In January 31, 2020, the World Health Organization declared a public health emergency of international concern for the outbreak of the novel Severe Acute Respiratory Syndrome Coronavirus-2 (SARS-CoV-2). The infection rapidly reached pandemic levels, with Veneto and Lombardy being the first Italian Regions to be heavily affected. The steep increasing number of coronavirus disease 2019 (COVID-19) cases led the Italian Government to issue executive orders for virus containment on a national level in March 11. By that date, patients with a confirmed diagnosis of COVID-19 were about 225.000 in Italy and 7.800 in Lazio, of which one third were in Rome (1). On a public health perspective, while COVID-19 patients requiring professional care were congesting the hospitals, a reorganization of healthcare service delivery, mostly nonurgent or non-emergent ones, was deemed necessary. Yet, early efforts were made to secure an efficient and safe elective patient care (e.g., social distancing, mobility restrictions, use of personal protective equipment).

Over the last decade, remote monitoring (RM) system has profoundly transformed the standard of care for patients with cardiac electronic implantable devices (CIEDs). RM provides access to the same information of an in-person evaluation (IPE) via data transmission from CIEDs to dedicated platforms easily accessible by medical staff. Mounting evidence has confirmed its usefulness for early detection of atrial and ventricular arrhythmias, as well as monitoring of system performance [e.g., lead failure and battery depletion $(2-5)$ ]. Additional benefits were also demonstrated among heart failure (HF) patients in terms of preventing unfavourable cardiovascular events and reducing hospital readmissions (6-10).

In line with the recently issued Heart Rhythm Society indications (11), our Cardiac Electrophysiology and Stimulation Center (CESC) revised the pre-existing workflow for CIED patients. The cornerstone of the novel management protocol was the improvement of RM coverage in order to prevent any potential risk of exposure for patients and healthcare providers, without jeopardizing quality of care. The purpose of the present study was to report the efficacy and patient satisfaction with the new CIED management protocol adopted during COVID-19 Italian lockdown.

\section{MATERIALS AND METHODS}

\section{Baseline Population and Study Period}

This single-center study was prospectively conducted at the Department of Cardiovascular and Respiratory Diseases, Umberto I Hospital, Sapienza University of Rome, Rome, Italy. Our study cohort included 3762 non-COVID-19 CIED patients who had been routinely followed by our Cardiac Electrophysiology and Stimulation Services.

Baseline, clinical and device characteristics, and follow-up data were prospectively collected in an Institutional Review Board approved database. Patients were asked to sign an informed consent for data collection and study participation. 


\section{CESC Workflow during COVID-19 Italian Lockdown}

Among 3762 patients with a CIED, 425 (11.4\%) patients had a single chamber implantable cardioverter defibrillator (ICD), $528(14.0 \%)$ a dual chamber ICD, $95(2.5 \%)$ a subcutaneous ICD in $95,283(7.7 \%)$ a cardiac resynchronization therapy (CRT) device, 231 (6.1\%) a single-chamber pacemaker (PMK), 1472 $(39.1 \%)$ a dual-chamber PMK, and $728(19.3 \%)$ an implantable loop recorder (ILR). Of them, $662(17.6 \%)$ patients were already in RM before COVID-19 outbreak.

A description of the CESC workflow is depicted in Figure 1.

Patients with an IPE scheduled between March and April 2020 were categorized into two groups: patients with a RM system prior to the lockdown (Group wRM ) and without a RM system (Group w/oRM).

-Group wRM: Scheduled IPEs for these patients were cancelled upon exclusion of any patient- and devicerelated issues assessed via a trans-telephonic contact and a device transmission performed within a week from the scheduled IPE appointment. For those reporting symptoms of HF or whose latest transmission documented a problem with system performance were followed up over the phone or, if necessary, scheduled for IPE.

-Group w/oRM: Patient without a RM system prior to the lockdown were further classified upon assessment of device features and compatibility for RM, individual clinical risk, and patient's agreement.

Patients implanted with a CIED without RM capabilities or not willing to receive a RM system were classified by reviewing the available medical charts and over a screening trans-telephonic contact. Two groups were identified:

- "Low-Risk" Group:

- CIED with a battery longevity [?] 12 months estimated during an IPE performed within the 6 months before study initiation;

- No device alerts detected during the last IPE performed within the 6 months before study initiation;

- No history of complex arrhythmias;

- No referred symptoms of acute decompensation and syncope.

- "High-Risk" Group:

- CIED with a battery longevity $<12$ months estimated during an IPE performed within the 6 months before study initiation;

- Abnormal lead impedance, threshold or sensing;

- Recent history ( $<3$ month) of acute heart failure requiring hospitalization;

- Appropriate and inappropriate ICD therapy detected in the last IPE;

- New onset of acute decompensation symptoms or referred syncope.

For "Low-Risk" patients the IPE was directly postponed within 6-9 months (long-term IPE) from the original in-hospital visit. Yet, a direct phone line with a team of specialized nurses was provided and patients were asked to report any new symptoms, emergency room visits or hospital admissions.

The remaining patients deemed being at "High-Risk" were scheduled for an IPE to be performed the same day or within one month from their original in-hospital examination.

Patients implanted with a CIED with RM capabilities and willing to receive the system were further categorized into two groups on the basis of RM system was assigned.

-Home-Delivered RM (Group hdRM): The device manufacturer agreed to provide the modem through a home delivery service. Once the modem was delivered, a specialized nurse contacted the patient in order to train and educate him/her on the use of the modem and to offer technical support when needed. A manual transmission within $24 \mathrm{~h}$ was requested to verify the correct activation of the modem, and only once the patient successfully completed the transmission, the IPE scheduled for March or April was cancelled.

-Office-Delivered RM (Group odRM): A short-term IPE (the same day or within a month from the original 
in-hospital visit) was scheduled. During the appointment, the RM system was delivered and a specialized nurse was responsible for patient training and education. After discharge, the patient was asked to perform a manual transmission from home.

For all previous and new patients with RM, every nurse referred to a physician for informed consent submission and patient's clinical management. Yet, a direct phone line with a team of specialized nurses was provided and patients were asked to report any technical issues with the system, as well as new symptoms, emergency room visits or hospital admissions. Compliance to drug therapy was monitored as well by phone contacts either periodically (monthly or bimonthly based on patient's risk profile and medical history) or in case of event recurrences. Pharmacological therapy titration and clinical event management were discussed among the clinical staff and, when necessary, IPE or hospital admission were programmed according to the clinical status of the patient. A dedicated pathway was created for IPEs in order to guarantee patient's safety.

\section{Patient satisfaction and anxiety status}

To evaluate the patients' acceptance and satisfaction with the RM program, two nurses administered (within a month since the first transmission) the Home Monitoring Acceptance and Satisfaction Questionnaire (HoMASQ) to all new patients who received the RM system (12). HoMASQ includes 12 items aimed at investigating five different aspects: 1- relationship with their healthcare provider, 2- ease of use of home monitoring technology, 3- related psychological aspects, 4- implications on general health and 5- overall satisfaction. Each item was rated on a five-point scale: from 0, strongly unfavourable, to 4, strongly favourable; an answer was considered favourable with a score [?] 2 .

Furthermore, the Generalized Anxiety Disorder 7-item (GAD-7) scale was administered by the same nurses to all new patients in RM. GAD-7 was administered to assess the level of safety or anxiety associated with RM and the psychological discomfort related to the home-delivery and office-delivery services. The questionnaire consists of seven items: 1- feeling nervous, anxious, or on edge; 2- being able to stop or control worrying; 3worrying too much about different things; 4 - trouble relaxing; 5 - being restless; 6 - becoming easily annoyed or irritable; 7- feeling afraid as if something awful might happen (13). Response options are "not at all" (scores as 0), "several days" (scores as 1), "more than half the days" (scores as 2) and "nearly every day" (scores as 3). The total score ranges from 0 to 21, with scores of 5, 10, and 15 representing the cut-off points for mild, moderate, and severe anxiety, respectively.

\section{Study Endpoints}

The aim of the study was to evaluate the efficacy and patient satisfaction with the new CESC protocol adopted during COVID-19 lockdown.

The primary endpoints were: 1) "RM Activation Time" in Group hdRM vs Group odRM, defined as the time to first independent manual transmission since modem was delivered; 2) Need for technical support in Group hdRM vs Group odRM, defined as the number of phone calls or IPEs the patient required due to technical problems activating the RM system.

The secondary endpoints were: 1) Number and type of clinically relevant RM transmissions in the overall RM population, including CIED alerts (battery depletion time, abnormal threshold, sensing and impedance measurements), arrhythmic events (atrial fibrillation (AF), supraventricular tachycardia (SVT), ventricular tachycardia (VT) and bradycardia), ICD therapies, HF-related alerts. 2) Number of emergent/urgent IPEs and hospitalizations; 3) Patient's acceptance and anxiety status with the new workflow.

\section{Statistical analysis}

Continuous data were described as mean +- SD, while median (interquartile range) was used for abnormal data. Categorical data was described with a number (percentage). All tests were 2 -sided, and a P-value $<$ .05 was considered statistically significant. The statistical analysis was performed using SPSS version 25.0 for Windows (IBM Software, Inc, Armonk, NY). 


\section{RESULTS}

\section{Demographic Characteristics}

The study population included 3762 CIED patients who have been followed-up at our Institution, $662(17.6 \%)$ of whom were in remote monitoring before the COVID-19 outbreak. Among the 3762 patients, 1114 had an IPE scheduled between March and April 2020 and were included in the study. Baseline characteristics are summarized in Table 1.

\section{Subgroup Characterization, RM Coverage and Distribution, and Study Endpoint}

Among 1114 CIED patients, 265 (23.8\%) were already in RM (Group wRM ). RM eligibility was checked for the remaining 849 (76.2\%) patients not in RM (Group w/oRM ). Five hundred seventeen (60.9\%) patients were ineligible for RM owing to connectivity or device-compatibility issues. Therefore, individual risk assessment was performed: a long-term IPE was scheduled for 423 (81.8\%) "Low-Risk" patients, whereas 94 (18.2\%) patients were deemed being at "High-Risk" and scheduled for a short-term IPE.

The remaining 332 patients implanted with a CIED with RM capabilities (Table 2) were further categorized into two groups on the basis of the modality the new RM system was assigned. In 229 (69.0\%) patients, the modem was directly delivered home (Group $h d R M)$ whereas in $103(31.0 \%)$, modem was assigned during an in-office visit (Group odRM).

Starting March $1^{\text {st }}, 229$ RM devices were shipped to each patient's home address (Group hdRM ). Mean delivery time was $2.8+-1.1$ days and by March $15^{\text {th }}$ all hdRM patients had received the modem.

In Group odRM ( $\mathrm{n}=103)$, an in-office visit was scheduled within an average of $4.2+-1.4$ days from the date of the original IPE. A dedicated pathway was created to guarantee patient's safety. Therefore, maximum 8 patients per day were scheduled and follow-ups were carried out in two different rooms. None of the patients, family members, or healthcare workers being affected by the virus during the 2-month study period. By March $27^{\text {th }}$ all Group odRM patients had received the device for RM.

Among the 332 patients who received the modem either at home or during an in-office visit, RM Activation Time was $<24 \mathrm{~h}$ in $271(81.6 \%)$ patients, between $24 \mathrm{~h}$ and $48 \mathrm{~h}$ in $36(10.8 \%)$, between $48 \mathrm{~h}$ and $72 \mathrm{~h}$ in 14 $(4.2 \%)$, and $>72 \mathrm{~h}$ in $11(3.3 \%)$. RM Activation Time within $24 \mathrm{~h}$ was significantly lower in patients older than 75 years old $(73.2 \%$ vs $88.2 \%$ in patients $<75$-year-old; $\mathrm{p}<0.01)$ and in patients living alone $(81.5 \%$ vs $89.4 \%$ in patients not living alone; $\mathrm{p}<0.01$ ).

No significative differences in RM activation time were documented between Group hdRM and Group odRM . The mean AT was 1.33 +- 0.83 days in Group $h d R M$ and $1.28+-0.81$ days in Group odRM $(\mathrm{p}=0.60)$. Specifically, a first manual transmission within 24 hours was recorded in 186 (81.2\%) patients from Group $h d R M$ and $87(84.5 \%)$ patients from Group odRM ( $\mathrm{p}=0.47$; Figure 2$)$

However, a trend toward a higher number of trans-telephonic technical support contacts due to problems completing the first transmission was observed in Group odRM [4 (4.2\%) patients vs 21 (9.9\%) patients; $\mathrm{p}=0.09]$. Moreover, 2 patients per group required a new IPE $(0.9 \%$ vs $2 \% ; \mathrm{p}=0.59)$; in one case a modem manufacturing defect was detected.

\section{Remote Monitoring Transmissions}

Number and type of clinically relevant RM transmissions in the overall RM population are summarized in Table 3. Among new RM patients enrolled, 4365 clinically relevant RM transmissions were registered: no significative differences in number and type of transmissions were reported between Group hdRM and Group odRM (13.4 vs 13.2 transmissions/patient; $\mathrm{p}=0.18$; Table 4).

Some critical alerts were recorded. Specifically, a syntomatic sinus pause (average pause length: 5.1 +1.7 seconds) was found in 12 patients with ILR: in $8(66.7 \%)$ a PMK was implanted, while in the other $4(33.3 \%)$ beta-blockers and/or amiodarone was discontinued, avoiding IPEs. Ten ILR patients (1\%) were 
diagnosed with sustained episodes of supraventricular tachycardia (SVT), 3 (30\%) of whom referring presyncopal or syncopal symptoms and requiring an electrophysiological study and radiofrequency catheter ablation. Newly diagnosed AF was reported in $26(2.6 \%)$ patients: $22(84.6 \%)$ were contacted by phone and prescribed with long-term oral anticoagulation according to their $\mathrm{CHA}_{2} \mathrm{DS}_{2} \mathrm{VASc}$ score. Episodes of sustained VT appropriately treated by the ICD were reported in 3 patients $(0.3 \%)$ : in two (66.7\%) cases amiodarone was added whereas catheter ablation was performed in one $(33.3 \%)$. Increased lead impedance without threshold or sensing changes was reported in $4(0.4 \%)$ patients.

Acute HF decompensation was suspected in $25(2.5 \%)$ patients via the OptiVol Alert (Medtronic) or HeartLogic (Boston) indexes: 10 (40\%) patients were managed trans-telephonically via loop diuretic titration, $7(28 \%)$ required hospitalization, and $8(32 \%)$ were scheduled for an IPE to optimize the pharmacological therapy.

\section{Emergent/urgent IPEs and hospitalizations}

Since the adoption of this new protocol, $230(20.6 \%)$ of the 1114 IPEs scheduled for March-April were performed, $33(3 \%)$ of which were urgent/emergent and required hospitalization in $24(2.1 \%)$ cases. Specifically, 4 "Low-Risk" patients required an IPE and 3 were admitted to the cardiology department or intensive care unit due to a PMK pocket infection, syncope secondary to high-degree atrioventricular block documented by the ILR requiring PMK implantation and advanced HF unresponsive to diuretic therapy in a CRT patient. Moreover, one "High Risk" patient with an ICD for primary prevention of sudden cardiac death was admitted to intensive care unit due to electric storm. Twenty-eight (2.5\%) of the 989 patients in RM required an urgent/emergent IPE and 19 (1.7\%) were admitted to the hospital. Moreover, a 78-year-old man with Advanced Heart Failure and multiple comorbidities died from Multi Organ Failure as a consequence of bacterial sepsis.

\section{Patient satisfaction and anxiety status}

The HoMASQ was completed by 287 of the 332 patients (86.4\%) within 30 days from first manual activation (mean $23.4+-2.3$ days). Similar results were recorded in the two groups. However, a trend toward a higher satisfaction and a better relationship with healthcare providers, even if not statistically significant, appeared from the answers of patients in Group odRM . The average and standard deviation of the five-point scale mean scores of each question and the percentage of favourable answers (score [?]2) are shown in Table 5.

On the other hand, GAD-7 was administered during IPE to 297 (89.5\%) newly enrolled RM patients in order to compare the level of anxiety associated to different RM enrolment protocols. No anxiety status was reported in $260(87.5 \%)$ patients, whereas mild, moderate, or severe levels of anxiety were documented in 28 $(9.4 \%), 8(2.7 \%)$ and $2(0.7 \%)$ of patients, respectively. Of note, a significantly higher number of patients in Group odRM referred a mild level of anxiety at the time of their in-office visit compared to those of Group $h d R M$ at the time they contacted the hospital to confirm receipt of the RM device.

\section{DISCUSSION}

Hereby, we describe our institutional experience on the feasibility and patient satisfaction with a novel CIED follow-up protocol during the COVID-19 Italian lockdown. Our main findings were the following:

- A reorganization of follow-up workflow with transition from IPE to RM was easily achieved in short period of time in a large population of CIED patients, without jeopardizing the quality of care of our service;

- Approximately $93 \%$ of the patients newly introduced to RM performed their first manual transmission within 48 hours. Despite a trend toward a higher number of trans-telephonic technical support contacts in Group $h d R M$, RM Activation Time was similar among patients who received the modem at home and those whose monitor was delivered during an IPE.

- No significant differences in number and type of transmissions were reported between these groups. Twenty-eight (2.5\%) urgent/emergent IPE were easily and safely planned in RM population when a trans-telephonic examination was not enough. 
- High degree of patient's satisfaction was reached in both groups while a higher anxiety status was registered when transmitter was delivered during an in-office visit.

Since January 2020, the steep increasing number of COVID-19 cases worldwide has had a huge impact on public health, conditioning medical activity and making standard, urgent, and emergent clinical management of patients more complex. As such, a rapid reorganization of healthcare service delivery was deemed necessary, including the in-office follow-up for patients with a CIED. As recommended by the Heart Rhythm Society COVID-19 Task Force (11), early efforts were made to secure an efficient and safe elective patient care (e.g., social distancing, mobility restrictions, use of personal protective equipment). In order to reduce virus exposure, the cornerstone of the novel management protocol was the improvement of RM coverage. As RM allows for transmission of data to dedicated platforms accessible to physicians, it represented an extremely valuable tool during the Italian COVID-19 lockdown. RM gives access to the same information of IPEs, which may contribute to the early detection of a wide range of arrhythmic manifestations, acute decompensation and device-related issues (6). As reported in several studies $(9,14)$, RM not only plays a central role in preventing hospitalizations, improving survival and quality of life of patients with CIEDs, but is also a cost-effective alternative to IPEs (15). In our experience RM allowed for an effective and safe delivery of healthcare services. A large number of our patients was rapidly introduced to RM, with high patient acceptance. Additionally, the continuous technical assistance offered by our medical staff led to a high degree of patients' compliance to the RM system; about $93 \%$ of our patients performed the first manual transmission within 48 hours from RM delivery with no difference observed between Group hdRM and Group odRM . Despite a longer RM Activation Time observed in people older than 75 years and/or who live alone, all patients successfully completed RM activation. These observations suggest that a RM-based follow-up protocol is feasible also in elderly patients and in those without significant in-home support (16). These subpopulations are also at higher-risk of COVID-19-related complications and mortality, due to a higher prevalence of comorbidities. However, RM allowed for a safe and uninterrupted patient care, avoiding the risk of in-hospital virus transmission.

Recent study (17), has shown a significant reduction in admissions for acute coronary syndromes during the Italian lockdown. Despite chest pain and other ischemia-related symptoms, many patients avoided hospital admission due to the increased risk of virus exposure. In this context, RM promoted a continuous patient assistance and monitoring and resulted in being a valuable tool to identify and timely treat arrhythmic/heart failure events, thereby avoiding potentially life-threatening consequences. In our population, no significant differences in number and type of transmissions were reported between Group hdRM andGroup odRM . Furthermore, an urgent/emergent IPE was planned in 28 (2.5\%) patients due to arrhythmic events and 19 $(1.7 \%)$ were admitted to the hospital.

From the psychological standpoint, the COVID-19 outbreak and the Italian lockdown were emotionally challenging and had a serious impact on the mental health of the entire population. In this context, we decided to administer the HoMASQ to evaluate RM acceptance and the GAD-7 questionnaire to assess the level of anxiety associated with the new RM-based follow-up and the modality of delivery of the modem. A high patient satisfaction rate was documented from the HoMASQ; specifically, patients reported an easy understanding of the device activation process, as well as high satisfaction with the use of the transmitter (12). Additionally, despite the ongoing pandemic and national lockdown, patients referred a sense of security and expressed interest in continuing with RM. Yet, GAD-7 results confirmed that SARS-CoV2 has increased patients' level of anxiety and psychological pressure, as confirmed in patients of Group odRM who reported a higher rate of anxiety associated with in-office delivery of the RM system.

\section{Study Limitations}

Several limitations should be considered. First, this is an observational study and carries the inherent limitations of this study design. Second, the study reflects the experience of a single medium-large volume Italian; therefore, generalizations should be considered with caution, as a result of the unique scenario of the Italian lockdown. 


\section{Conclusions}

RM was effective, safe, and highly tolerated by CIED patients during the Italian lockdown. Our findings confirm the efficacy of this approach to reduce in-hospital visits, guaranteeing patients' safety and quality of care.

Acknowledgements: none.

\section{References}

1. https://coronavirus.jhu.edu/map.html 05.16.2020

2. Varma N, Michalski J, Epstein AE, et al. Automatic remote monitoring of implantable cardioverterdefibrillator lead and generator performance: the Lumos-T Safely RedUceS RouTine Office Device Follow-Up (TRUST) trial. Circ Arrhythm Electrophysiol 2010;3:428-36.

3. Guedon-Moreau L, Chevalier P, Marquie C, et al. Contributions of remote monitoring to the follow-up of implantable cardioverter-defibrillator leads under advisory. Eur Heart J 2010;31:2246-52.

4. Varma N, Epstein AE, Irimpen A, et al. Efficacy and safety of automatic remote monitoring for implantable cardioverter-defibrillator follow-up: the Lumos-T Safely Reduces Routine Office Device Follow-up (TRUST) trial. Circulation 2010;122:325-32.

5. Capucci A, Santini M, Padeletti L, et al. Monitored atrial fibrillation duration predicts arterial embolic events in patients suffering from bradycardia and atrial fibrillation implanted with antitachycardia pacemakers. J Am Coll Cardiol 2005;46:1913-20.

6. Boehmer JP, Hariharan R, Devecchi FG, et al. A Multisensor Algorithm Predicts Heart Failure Events in Patients With Implanted Devices: Results From the MultiSENSE Study. JACC Heart Fail. 2017 Mar;5(3):216-225.

7. Forleo GB, Tesauro M, Panattoni G, et al. Impact of Continuous Intracardiac ST-segment Monitoring on Mid-Term Outcomes of ICD-implanted Patients With Coronary Artery Disease. Early Results of a Prospective Comparison With Conventional ICD Outcomes. Heart. 2012 Mar;98(5):402-7.

8. Forleo GB, Panattoni G, Schirripa V, et al. Device monitoring of heart failure in cardiac resynchronization therapy device recipients: a single-center experience with a novel multivector impedance monitoring system. J Cardiovasc Med, 14(10),726-732.

9. Boehmer JP, Hariharan R, Devecchi FG, et al. A Multisensor Algorithm Predicts Heart Failure Events in Patients With Implanted Devices: Results From the MultiSENSE Study. JACC Heart Fail. 2017 Mar;5(3):216-225.

10. Della Rocca DG, Albanese M, Placidi F, et al. Feasibility of automated detection of sleep apnea using implantable pacemakers and defibrillators: a comparison with simultaneous polysomnography recording. J Interv Card Electrophysiol. 2019 Dec;56(3):327-333.

11. Lakkireddy DR, Chung MK, et al. Guidance for Cardiac Electrophysiology During the Coronavirus (COVID-19). Pandemic from the Heart Rhythm Society COVID-19 Task Force; Electrophysiology Section of the American College of Cardiology; and the Electrocardiography and Arrhythmias Committee of the Council on Clinical Cardiology, American Heart Association. HeartRhythm 2020.

12. Ricci RP, Morichelli L. Workflow, time and patient satisfaction from the perspectives of Home Monitoring. Europace (2013)15,i49-i53.

13. Spitzer RL, Kroenke K, Williams JBW, Lowe B. (2006). A Brief Measure for Assessing Generalized Anxiety Disorder. Archives of Internal Medicine, 166(10),1092.

14. Hindricks G, Taborsky M, Glikson M, et al. Implant-based multiparameter telemonitoring of patients with heart failure (IN-TIME): a randomised controlled trial. Lancet 2014;384:583-590.

15. Crossley GH. Further evidence that remote monitoring is cost-effective: it's time for all to adopt. HeartRhytm 2017;14:58.

16. Artico J, Zecchin M, Zorzin Fantasia A, et al. Long-term Patient Satisfaction With Implanted Device Remote Monitoring: A Comparison Among Different Systems. J Cardiovasc Med 2019 Aug;20(8):542550 . 
17. De Filippo O, D'Ascenzo F, Angelini F, et al. Reduced rate of hospital admissions for ACS during Covid-19 outbreak in northern Italy. N Engl J Med.

\section{FIGURE LEGENDS}

Figure 1: CIED management protocol adopted during COVID-19 Italian lockdown. CIED = Cardiac Implantable Electronic Device, Group hdRM = RM home delivered, Group odRM = RM in office delivered, IPE $=$ In Personal Evaluation, $\mathrm{RM}=$ Remote Monitoring.

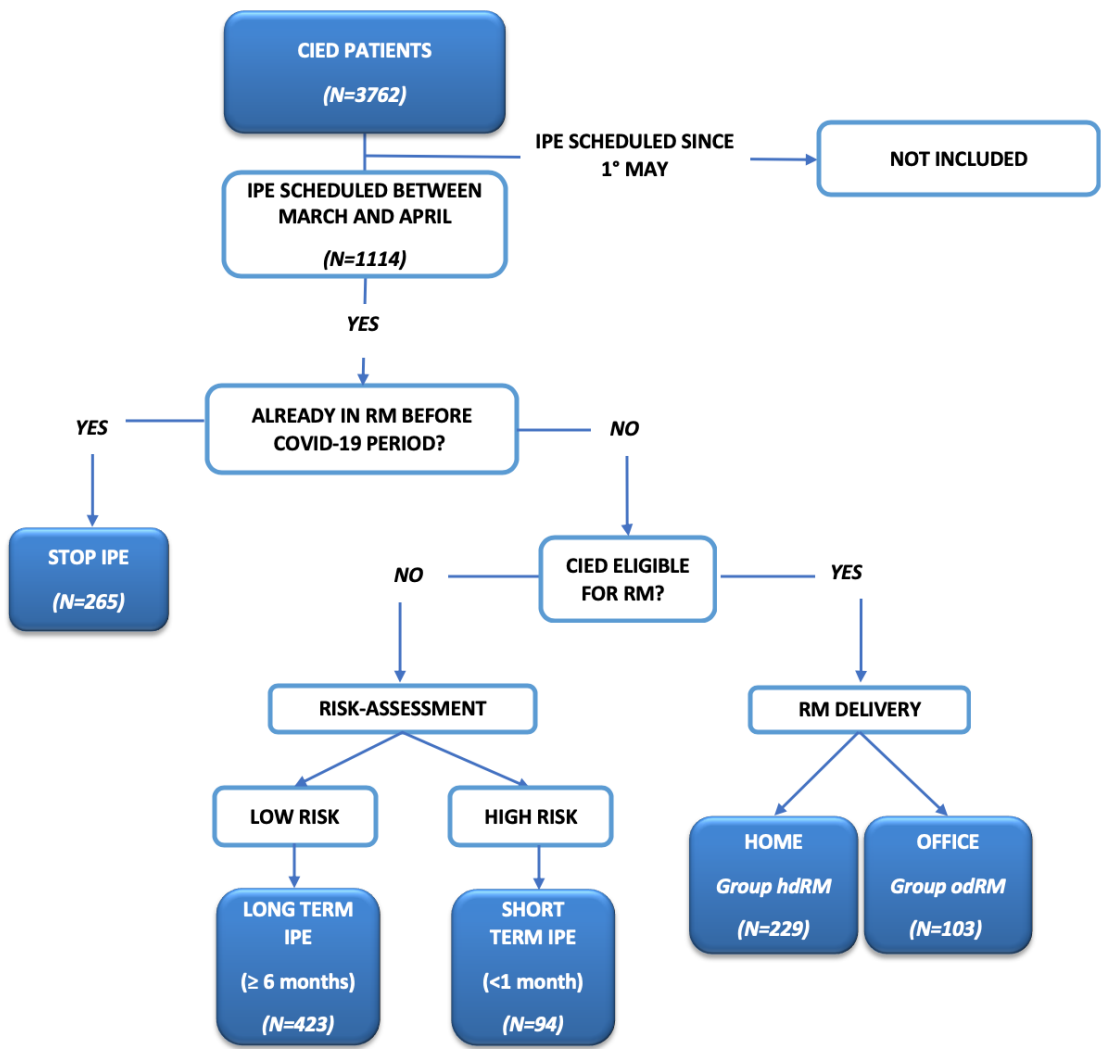

Figure 2: Remote Monitoring Activation Time in Group hdRM and Group odRM. Group hdRM $=\mathrm{RM}$ home delivered, Group odRM $=\mathrm{RM}$ in office delivered. 


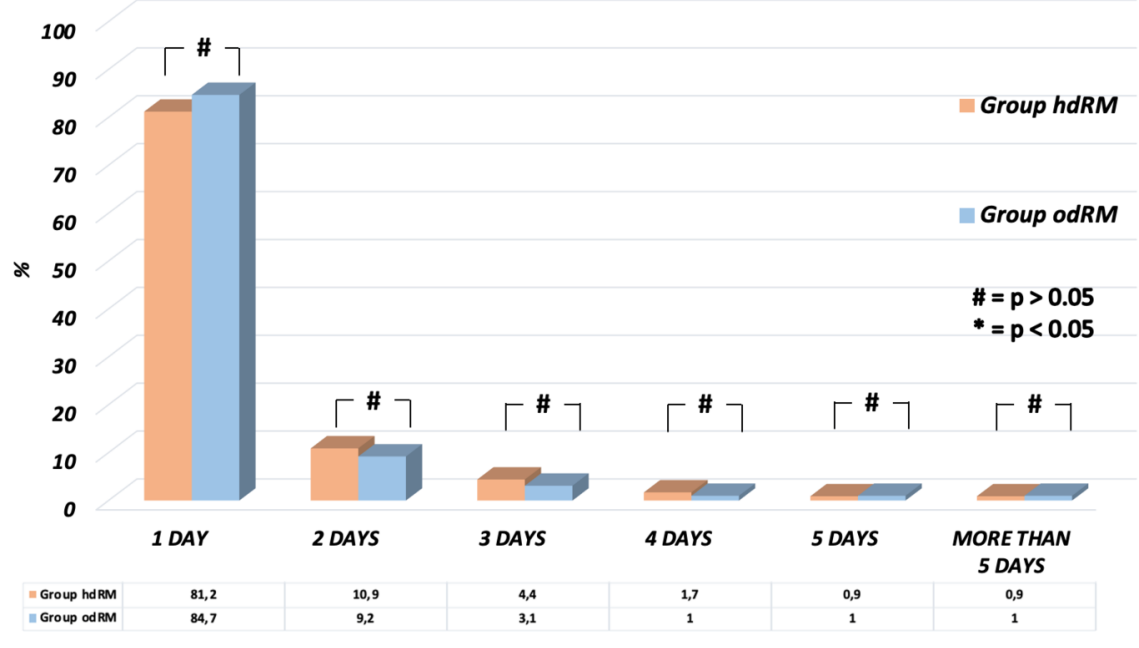

Figure 3: GAD-7 results comparing in Group hdRM and Group odRM.GAD-7 = Generalized Anxiety Disorder 7-item, Group hdRM = RM home delivered, Group odRM $=\mathrm{RM}$ in office delivered.

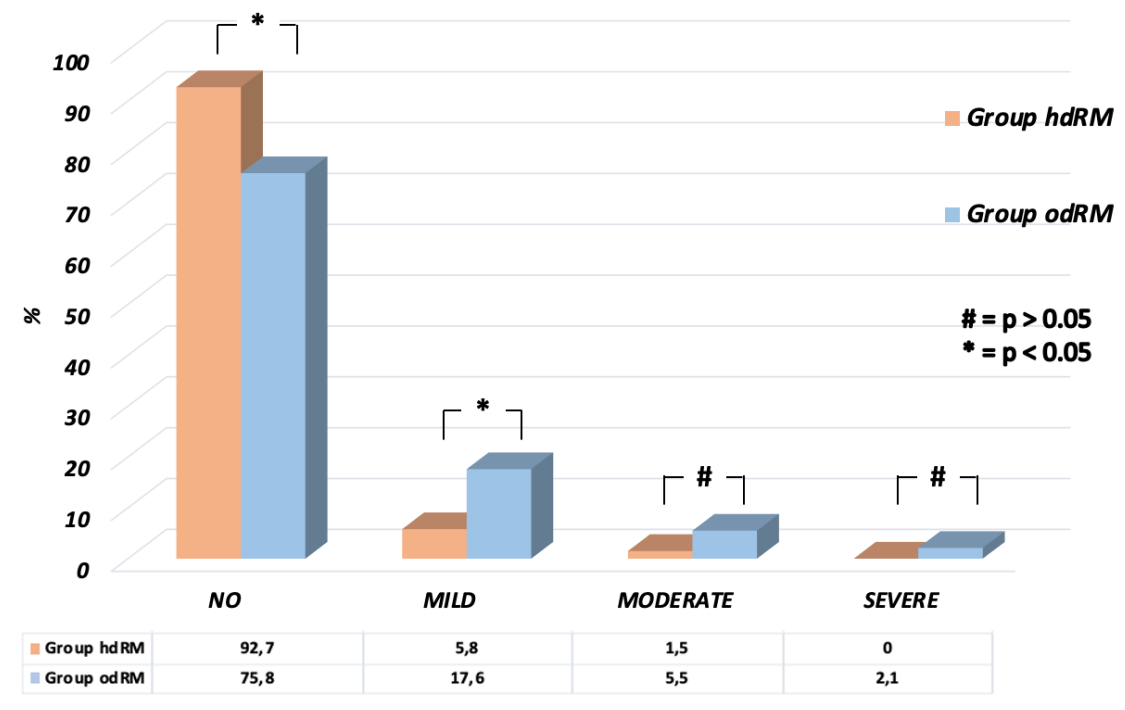

\begin{tabular}{lllll}
\hline Demographics & $\begin{array}{l}\text { All patients } \\
(\mathrm{n}=1114)\end{array}$ & $\begin{array}{l}\text { Group wRM } \\
(\mathrm{n}=265)\end{array}$ & $\begin{array}{l}\text { Group w/oRM } \\
(\mathrm{n}=849)\end{array}$ & p-value \\
\hline $\begin{array}{l}\text { Age, yrs } \\
\text { Male, n (\%) }\end{array}$ & $64.5 \pm 18.4$ & $63.3 \pm 17.9$ & $64.2 \pm 18.3$ & 0.74 \\
$\begin{array}{l}\text { IIED } \\
\text { ICD, n (\%) }\end{array}$ & $429(57.3)$ & $149(56.2)$ & $489(57.6)$ & 0.69 \\
$\begin{array}{l}\text { Single Chamber, n } \\
(\%)\end{array}$ & $228(20.5)$ & $100(37.7)$ & $329(38.8)$ & 0.76 \\
$\begin{array}{l}\text { Dual Chamber, n } \\
(\%)\end{array}$ & $177(15.8)$ & $57(21.5)$ & $171(20.1)$ & 0.37 \\
S-ICD, n (\%) & $24(2.2)$ & $34(12.8)$ & $143(16.8)$ & 0.09 \\
& & $9(3.4)$ & $15(1.8)$ & 0.22
\end{tabular}




\begin{tabular}{|c|c|c|c|c|}
\hline Demographics & $\begin{array}{l}\text { All patients } \\
(\mathrm{n}=1114)\end{array}$ & $\begin{array}{l}\text { Group wRM } \\
(\mathrm{n}=265)\end{array}$ & $\begin{array}{l}\text { Group w/oRM } \\
(\mathrm{n}=849)\end{array}$ & $\mathrm{p}$-value \\
\hline$\overline{\mathrm{PM}, \mathrm{n}(\%)}$ & $425(38.1)$ & $102(38.5)$ & $323(38.0)$ & 0.89 \\
\hline $\begin{array}{l}\text { Single Chamber, } \mathrm{n} \\
(\%)\end{array}$ & $61(5.5)$ & $18(6.8)$ & $43(5.1)$ & 0.28 \\
\hline $\begin{array}{l}\text { Dual Chamber, } \mathrm{n} \\
(\%)\end{array}$ & $364(32.6)$ & $84(31.7)$ & $280(33.0)$ & 0.28 \\
\hline ILR, n (\%) & $171(15.4)$ & $35(13.2)$ & $136(16.0)$ & 0.27 \\
\hline CRT, n (\%) & $89(8.0)$ & $19(7.2)$ & $70(8.2)$ & 0.57 \\
\hline \multicolumn{5}{|l|}{ Heart Disease } \\
\hline No, n $(\%)$ & $101(9.1)$ & $25(9.4)$ & $76(8.9)$ & 0.81 \\
\hline $\begin{array}{l}\text { Ischaemic HD, n } \\
(\%)\end{array}$ & $451(40.5)$ & $95(35.8)$ & $356(41.9)$ & 0.08 \\
\hline Valvular HD, n (\%) & $116(10.4)$ & $24(9.1)$ & $92(10.8)$ & 0.41 \\
\hline $\begin{array}{l}\text { Channelopathies, } \mathrm{n} \\
(\%)\end{array}$ & $12(1.1)$ & $2(0.8)$ & $10(1.2)$ & 1 \\
\hline $\begin{array}{l}\text { Congenital HD, n } \\
(\%)\end{array}$ & $7(0.6)$ & $1(0.4)$ & $6(0.7)$ & 1 \\
\hline Others, n $(\%)$ & $22(2)$ & $5(1.9)$ & $17(2.0)$ & 0.92 \\
\hline \multicolumn{5}{|l|}{ NYHA } \\
\hline $\mathrm{I}, \mathrm{n}(\%)$ & $278(25.0)$ & $63(23.8)$ & $215(25.3)$ & 0.61 \\
\hline II, n $(\%)$ & $473(42.5)$ & $117(44.2)$ & $356(41.9)$ & 0.52 \\
\hline III, n (\%) & $330(29.6)$ & $78(29.4)$ & $252(29.7)$ & 0.92 \\
\hline IV, n (\%) & $33(2.9)$ & $7(2.6)$ & $26(3.1)$ & 0.73 \\
\hline $\begin{array}{l}\text { LVEF [range] } \\
\text { Comorbidities }\end{array}$ & $46 \pm 12[20-60]$ & $44 \pm 11[20-60]$ & $45 \pm 12[20-60]$ & 0.81 \\
\hline $\begin{array}{l}\text { Diabetes mellitus, } \mathrm{n} \\
(\%)\end{array}$ & $413(37.1)$ & $101(38.1)$ & $312(36.7)$ & 0.69 \\
\hline $\begin{array}{l}\text { Chronic Obstructive } \\
\text { Pulmonary Disease, } \\
\text { n (\%) }\end{array}$ & $187(16.8)$ & $40(15.1)$ & $147(17.3)$ & 0.40 \\
\hline Hypertension, n (\%) & $601(53.9)$ & $146(55.1)$ & $455(53.6)$ & 0.67 \\
\hline $\begin{array}{l}\text { Chronic Kidney } \\
\text { Disease, n (\%) }\end{array}$ & $231(20.7)$ & $52(19.6)$ & $179(21.1)$ & 0.61 \\
\hline
\end{tabular}

\section{TABLES}

Table 1. Baseline characteristics of study population $(\mathrm{N}=1114) . \mathrm{CRT}=$ Cardiac Resynchronization Therapy, Group wRM = patients in RM prior to the lockdown, Group w/oRM = patients without a RM system, HD = Heart Disease, ICD = Implantable Cardioverter Defibrillator, ILR = Implantable Loop Recorder, LVEF = Left Ventricular Ejection Fraction, NYHA = New York Heart Association, PMK = Pacemaker, S-ICD = Subcutaneous Implantable Cardioverter Defibrillator.

\begin{tabular}{lllll}
\hline Demographics & $\begin{array}{l}\text { Patients RM } \\
\text { enrolled }(\mathrm{n}=332)\end{array}$ & $\begin{array}{l}\text { Group hdRM } \\
(\mathrm{n}=229)\end{array}$ & $\begin{array}{l}\text { Group odRM } \\
(\mathrm{n}=103)\end{array}$ & p-value \\
\hline Age, yrs & $64.2 \pm 17.4$ & $63.8 \pm 17.2$ & $65.5 \pm 18.0$ & 0.67 \\
$\begin{array}{l}\text { Male, n }(\%) \\
\text { CIED }\end{array}$ & $196(59.0)$ & $135(58.9)$ & $61(59.2)$ & 1 \\
ICD, n (\%) & $131(39.5)$ & $90(39.3)$ & $41(39.8)$ & 0.92
\end{tabular}




\begin{tabular}{|c|c|c|c|c|}
\hline Demographics & $\begin{array}{l}\text { Patients RM } \\
\text { enrolled }(n=332)\end{array}$ & $\begin{array}{l}\text { Group hdRM } \\
(\mathrm{n}=229)\end{array}$ & $\begin{array}{l}\text { Group odRM } \\
(\mathrm{n}=103)\end{array}$ & p-value \\
\hline $\begin{array}{l}\text { Single Chamber, } \mathrm{n} \\
(\%)\end{array}$ & $56(16.9)$ & $37(16.2)$ & $19(18.4)$ & 0.60 \\
\hline $\begin{array}{l}\text { Dual Chamber, } \mathrm{n} \\
(\%)\end{array}$ & $58(17.5)$ & $40(17.4)$ & $18(17.5)$ & 1 \\
\hline S-ICD, n $(\%)$ & $17(5.1)$ & $13(5.7)$ & $4(3.9)$ & 0.49 \\
\hline PM, n \% & $129(38.8)$ & $89(38.9)$ & $40(38.8)$ & 1 \\
\hline $\begin{array}{l}\text { Single Chamber, } \mathrm{n} \\
(\%)\end{array}$ & $20(6.0)$ & $13(5.7)$ & $7(6.8)$ & 0.69 \\
\hline $\begin{array}{l}\text { Dual Chamber, } \mathrm{n} \\
(\%)\end{array}$ & $109(32.8)$ & $76(33.2)$ & $33(32.0)$ & 0.84 \\
\hline ILR, n $(\%)$ & $53(16.0)$ & $37(16.1)$ & $16(15.6)$ & 0.89 \\
\hline CRT, n (\%) & $19(5.7)$ & $13(5.7)$ & $6(5.8)$ & 1 \\
\hline \multicolumn{5}{|l|}{ Heart Disease } \\
\hline No, n $(\%)$ & $33(9.9)$ & $23(10.0)$ & $10(9.7)$ & 0.92 \\
\hline $\begin{array}{l}\text { Ischaemic HD, n } \\
(\%)\end{array}$ & $127(38.3)$ & $89(38.9)$ & $38(36.9)$ & 0.73 \\
\hline Valvular HD, n (\%) & $36(10.7)$ & $23(10.0)$ & $13(12.6)$ & 0.48 \\
\hline $\begin{array}{l}\text { Channelopathies, } \mathrm{n} \\
(\%)\end{array}$ & $5(1.5)$ & $3(1.3)$ & $2(2.0)$ & 1 \\
\hline $\begin{array}{l}\text { Congenital HD, n } \\
(\%)\end{array}$ & $2(0.6)$ & $1(0.4)$ & $1(1.0)$ & 1 \\
\hline $\begin{array}{l}\text { Others, n (\%) } \\
\text { NYHA }\end{array}$ & $7(2.1)$ & $5(2.2)$ & $2(2.0)$ & 1 \\
\hline $\mathrm{I}, \mathrm{n}(\%)$ & $90(27.1)$ & $63(27.5)$ & $27(26.2)$ & 0.81 \\
\hline $\mathrm{II}, \mathrm{n}(\%)$ & $146(43.9)$ & $99(43.2)$ & $47(45.6)$ & 0.68 \\
\hline III, n (\%) & $87(26.2)$ & $60(26.2)$ & $27(26.2)$ & 1 \\
\hline $\mathrm{IV}, \mathrm{n}(\%)$ & $9(2.8)$ & $7(3.1)$ & $2(2.0)$ & 1 \\
\hline $\begin{array}{l}\text { LVEF [range] } \\
\text { Comorbidities }\end{array}$ & $45 \pm 12[20-60]$ & $44 \pm 12[20-60]$ & $47 \pm 12[20-60]$ & 0.43 \\
\hline $\begin{array}{l}\text { Diabetes mellitus, } \mathrm{n} \\
(\%)\end{array}$ & $123(37.0)$ & $87(38.0)$ & $36(35.0)$ & 0.60 \\
\hline $\begin{array}{l}\text { Chronic Obstructive } \\
\text { Pulmonary Disease, } \\
\text { n (\%) }\end{array}$ & $54(16.3)$ & $40(17.5)$ & $14(16.5)$ & 0.38 \\
\hline Hypertension, n (\%) & $174(52.4)$ & $123(53.7)$ & $51(49.5)$ & 0.48 \\
\hline $\begin{array}{l}\text { Chronic Kidney } \\
\text { Disease, n (\%) }\end{array}$ & $67(20.2)$ & $46(20.1)$ & $21(20.4)$ & 1 \\
\hline
\end{tabular}

Table 2. Baseline characteristics of patients enrolled in RM adopting new CESC protocol $(\mathbf{N}=332)$. $\quad$ CRT $=$ Cardiac Resynchronization Therapy, Group $w R M=$ patients in RM prior to the lockdown, Group w/oRM = patients without a RM system, HD = Heart Disease, ICD = Implantable Cardioverter Defibrillator, ILR = Implantable Loop Recorder, LVEF = Left Ventricular Ejection Fraction, NYHA $=$ New York Heart Association, PMK = Pacemaker, S-ICD = Subcutaneous Implantable Cardioverter Defibrillator.

Table 3. Number and type of clinically relevant RM transmissions. AHRE $=$ Atrial High Rate Episode, CIED = Cardiovascular Implantable Electronic Devices, ICD = Implantable Cardioverter Defibrillator, RM = Remote Monitoring, SVT = SupraVentricular Tachycardia, VT = Ventricular Tachycardia. 


\begin{tabular}{|c|c|c|c|}
\hline & $\begin{array}{l}\text { Overall RM population } \\
(\mathrm{n}=989)\end{array}$ & $\begin{array}{l}\text { New RM enrolled } \\
(\mathrm{n}=332)\end{array}$ & $\mathrm{P}$-value \\
\hline Transmissions, $\mathrm{n}$ & 13157 & 4365 & \\
\hline $\begin{array}{l}\text { Transmission Type } \\
\text { CIED parameters } \\
\text { problems, n }(\%)\end{array}$ & $26(0.2)$ & $8(0.2)$ & 0.86 \\
\hline AHRE, n $(\%)$ & $10502(79.8)$ & $3473(79.6)$ & 0.72 \\
\hline SVT, n (\%) & $442(3.4)$ & $137(3.1)$ & 0.48 \\
\hline $\mathrm{VT}, \mathrm{n}(\%)$ & $79(0.6)$ & $16(0.4)$ & 0.07 \\
\hline ICD Shock, n (\%) & $7(0.1)$ & $2(0.1)$ & 1 \\
\hline Bradycardia, n (\%) & $1750(13.3)$ & $596(13.6)$ & 0.55 \\
\hline Symptoms, n (\%) & $263(2.0)$ & $107(2.4)$ & 0.07 \\
\hline \multirow[t]{2}{*}{$\begin{array}{l}\text { Heart failure monitoring, } \\
\mathrm{n}(\%)\end{array}$} & $88(0.7)$ & $26(0.6)$ & 0.61 \\
\hline & Group hdRM $(\mathrm{n}=229)$ & Group odRM $(\mathrm{n}=103)$ & $\mathrm{P}$-value \\
\hline $\begin{array}{l}\text { Transmissions, } \mathrm{n} \\
\text { Transmission Type }\end{array}$ & 3043 & 1322 & \\
\hline $\begin{array}{l}\text { CIED parameters } \\
\text { problems, } \mathrm{n}(\%)\end{array}$ & $6(0.2)$ & $2(0.2)$ & 1 \\
\hline AHRE, n (\%) & $2357(79.8)$ & $1017(79.6)$ & 0.70 \\
\hline SVT, n (\%) & $96(3.4)$ & $41(3.1)$ & 0.92 \\
\hline $\mathrm{VT}, \mathrm{n}(\%)$ & $11(0.6)$ & $5(0.4)$ & 1 \\
\hline ICD Shock, n (\%) & $2(0.1)$ & $0(0.1)$ & 1 \\
\hline Bradycardia, n (\%) & $423(13.3)$ & $173(13.6)$ & 0.47 \\
\hline Symptoms, n (\%) & $74(2.0)$ & $33(2.4)$ & 0.89 \\
\hline $\begin{array}{l}\text { Heart failure monitoring, } \\
\mathrm{n}(\%)\end{array}$ & $18(0.7)$ & $8(0.6)$ & 1 \\
\hline
\end{tabular}

Table 4. Number and type of clinically relevant transmissions in patients enrolled in RM adopting new CIED protocol. AHRE $=$ Atrial High Rate Episode, CIED = Cardiovascular Implantable Electronic Devices, Group hdRM = RM home delivered, Group odRM = RM in office delivered, ICD = Implantable Cardioverter Defibrillator, SVT $=$ SupraVentricular Tachycardia, VT $=$ Ventricular Tachycardia.

\begin{tabular}{|c|c|c|c|c|}
\hline $\begin{array}{l}\text { ITEM } \\
\text { DESCRIPTION }\end{array}$ & $\begin{array}{l}\text { Group hdRM } \\
(\mathrm{n}=216)\end{array}$ & $\begin{array}{l}\text { Group hdRM } \\
(\mathrm{n}=216)\end{array}$ & $\begin{array}{l}\text { Group odRM } \\
(\mathrm{n}=71)\end{array}$ & $\begin{array}{l}\text { Group odRM } \\
(\mathrm{n}=71)\end{array}$ \\
\hline & Mean \pm SD & $\begin{array}{l}\text { Favourable } \\
\text { responses \% }\end{array}$ & Mean $\pm \mathrm{SD}$ & $\begin{array}{l}\text { Favourable } \\
\text { responses \% }\end{array}$ \\
\hline $\begin{array}{l}\text { Relationship with } \\
\text { healthcare } \\
\text { provider }\end{array}$ & $\begin{array}{l}\text { Relationship with } \\
\text { healthcare } \\
\text { provider }\end{array}$ & $\begin{array}{l}\text { Relationship with } \\
\text { healthcare } \\
\text { provider }\end{array}$ & $\begin{array}{l}\text { Relationship with } \\
\text { healthcare } \\
\text { provider }\end{array}$ & $\begin{array}{l}\text { Relationship with } \\
\text { healthcare } \\
\text { provider }\end{array}$ \\
\hline $\begin{array}{l}\text { Was the } \\
\text { explanation of } \\
\text { RM system } \\
\text { exhaustive? }\end{array}$ & $3.04 \pm 0.82$ & $95 \%$ & $3.15 \pm 0.87$ & $90 \%$ \\
\hline
\end{tabular}




\begin{tabular}{|c|c|c|c|c|}
\hline $\begin{array}{l}\text { ITEM } \\
\text { DESCRIPTION }\end{array}$ & $\begin{array}{l}\text { Group hdRM } \\
(\mathrm{n}=216)\end{array}$ & $\begin{array}{l}\text { Group hdRM } \\
(\mathrm{n}=216)\end{array}$ & $\begin{array}{l}\text { Group odRM } \\
(\mathrm{n}=71)\end{array}$ & $\begin{array}{l}\text { Group odRM } \\
(\mathrm{n}=71)\end{array}$ \\
\hline $\begin{array}{l}\text { During the } \\
\text { contacts have you } \\
\text { received clear } \\
\text { information? }\end{array}$ & $2.97 \pm 0.80$ & $94 \%$ & $2.75 \pm 0.89$ & $89 \%$ \\
\hline $\begin{array}{l}\text { Easiness of use of } \\
\text { this new } \\
\text { technology }\end{array}$ & $\begin{array}{l}\text { Easiness of use of } \\
\text { this new } \\
\text { technology }\end{array}$ & $\begin{array}{l}\text { Easiness of use of } \\
\text { this new } \\
\text { technology }\end{array}$ & $\begin{array}{l}\text { Easiness of use of } \\
\text { this new } \\
\text { technology }\end{array}$ & $\begin{array}{l}\text { Easiness of use of } \\
\text { this new } \\
\text { technology }\end{array}$ \\
\hline $\begin{array}{l}\text { How was it simple } \\
\text { to connect and } \\
\text { turn on the } \\
\text { transmitter? }\end{array}$ & $3.19 \pm 0.73$ & $96 \%$ & $2.87 \pm 0.85$ & $91 \%$ \\
\hline $\begin{array}{l}\text { How was simple } \\
\text { to assure } \\
\text { transmissions? }\end{array}$ & $3.27 \pm 0.76$ & $95 \%$ & $2.96 \pm 0.86$ & $90 \%$ \\
\hline $\begin{array}{l}\text { Psychological } \\
\text { aspects related to } \\
\text { remote control }\end{array}$ & $\begin{array}{l}\text { Psychological } \\
\text { aspects related to } \\
\text { remote control }\end{array}$ & $\begin{array}{l}\text { Psychological } \\
\text { aspects related to } \\
\text { remote control }\end{array}$ & $\begin{array}{l}\text { Psychological } \\
\text { aspects related to } \\
\text { remote control }\end{array}$ & $\begin{array}{l}\text { Psychological } \\
\text { aspects related to } \\
\text { remote control }\end{array}$ \\
\hline $\begin{array}{l}\text { How much did } \\
\text { the transmitter } \\
\text { affect your daily } \\
\text { activity? }\end{array}$ & $3.05 \pm 0.88$ & $91 \%$ & $3.05 \pm 0.86$ & $92 \%$ \\
\hline $\begin{array}{l}\text { Did you ever feel } \\
\text { observed by the } \\
\text { transmitter? }\end{array}$ & $3.17 \pm 0.86$ & $96 \%$ & $3.1 \pm 0.80$ & $95 \%$ \\
\hline $\begin{array}{l}\text { Does the } \\
\text { transmitter } \\
\text { provide you a } \\
\text { sense of security? }\end{array}$ & $2.89 \pm 0.82$ & $92 \%$ & $3.06 \pm 0.84$ & $93 \%$ \\
\hline $\begin{array}{l}\text { Is the transmitter } \\
\text { a bother? }\end{array}$ & $3.28 \pm 0.79$ & $93 \%$ & $3.14 \pm 0.85$ & $93 \%$ \\
\hline $\begin{array}{l}\text { Implication of } \\
\text { RM on general } \\
\text { health }\end{array}$ & $\begin{array}{l}\text { Implication of } \\
\text { RM on general } \\
\text { health }\end{array}$ & $\begin{array}{l}\text { Implication of } \\
\text { RM on general } \\
\text { health }\end{array}$ & $\begin{array}{l}\text { Implication of } \\
\text { RM on general } \\
\text { health }\end{array}$ & $\begin{array}{l}\text { Implication of } \\
\text { RM on general } \\
\text { health }\end{array}$ \\
\hline $\begin{array}{l}\text { How much } \\
\text { important was } \\
\text { the information } \\
\text { for physician? }\end{array}$ & $3.3 \pm 0.75$ & $95 \%$ & $2.94 \pm 0.92$ & $90 \%$ \\
\hline $\begin{array}{l}\text { Do you think that } \\
\text { HM had positive } \\
\text { effects on your } \\
\text { health? }\end{array}$ & $3.09 \pm 0.81$ & $95 \%$ & $2.87 \pm 0.89$ & $91 \%$ \\
\hline $\begin{array}{l}\text { Overall } \\
\text { satisfaction of RM }\end{array}$ & $\begin{array}{l}\text { Overall } \\
\text { satisfaction of RM }\end{array}$ & $\begin{array}{l}\text { Overall } \\
\text { satisfaction of RM }\end{array}$ & & \\
\hline $\begin{array}{l}\text { Are you satisfied } \\
\text { of RM } \\
\text { organization? }\end{array}$ & $3.08 \pm 0.75$ & $95 \%$ & $2.91 \pm 0.84$ & $93 \%$ \\
\hline
\end{tabular}




\begin{tabular}{lllll}
\hline $\begin{array}{l}\text { ITEM } \\
\text { DESCRIPTION }\end{array}$ & $\begin{array}{l}\text { Group hdRM } \\
(\mathrm{n}=216)\end{array}$ & $\begin{array}{l}\text { Group hdRM } \\
(\mathrm{n}=216)\end{array}$ & $\begin{array}{l}\text { Group odRM } \\
(\mathrm{n}=71)\end{array}$ & $\begin{array}{l}\text { Group odRM } \\
(\mathrm{n}=71)\end{array}$ \\
\hline $\begin{array}{l}\text { Do you want to } \\
\text { continue to use }\end{array}$ & $3.42 \pm 0.79$ & $96 \%$ & $3.29 \pm 0.87$ & $91 \%$ \\
RM technology? & & & & \\
\hline
\end{tabular}

Table 5. HoMASQ results. Group hdRM $=\mathrm{RM}$ home delivered, Group hoRM $=\mathrm{RM}$ in office delivered, HoMASQ $=$ Home Monitoring Acceptance and Satisfaction Questionary. 